\title{
Tanulmány
}

\section{Sergei Kuzeev \\ Language and Consciousness: Towards the Path of Synergy}

\begin{abstract}
While physicalist interpretations of human consciousness have been the major focus in the philosophy of mind and cognitive science during the last decades, many existing proposals expressly link phenomenal consciousness with human linguistic ability and build on the idea that we acquire cognitive access to consciousness through "higher-order" verbal thinking. Accepting this premise and the epistemological consequences of Jackson's Knowledge Argument, this paper argues that the study of phenomenal knowledge as the one mediated by language might grow into a novel and promising research agenda for cognitive linguistics.

Keywords: phenomenal concepts, language and consciousness, knowledge argument
\end{abstract}

\section{Introduction}

Today's philosophy of mind is still primarily concerned with the legacy of Cartesian dualismi.e. the causal relations between consciousness and the physical brain, also known as the "mind-body problem"- and takes only a peripheral interest in natural language, viewed, at best, as an auxiliary tool pertaining to the higher levels of cognition. However, since the philosophy of mind provides a theoretical interface for the cognitive science, where the role of linguistic mechanisms has typically been of a greater import, and given the recent advances in the fields of artificial intelligence, consciousness studies, and neuroscience, the disregard for natural language seems to no longer be a viable strategy. This paper, therefore, aims at sketching the pathways, along which linguistic theory can contribute to the solution of the consciousness debate, and at outlining the conceptual basis for the prospective theory of phenomenal discourse that is currently in its initial stage.

The rationale behind this research program stems from the Knowledge Argument proposed by Jackson to challenge the reductionist thesis that the phenomenal character of perceptual experiences can be conclusively interpreted in purely physicalist terms. This argument legitimized the notion of "phenomenal concepts" that refer to the subjective quality of phenomenal experience. By assuming, as some researchers in the philosophy of mind suggest, that the phenomenal knowledge thus acquired is (at least to a certain degree) contingent on linguistic ability, I argue that studying phenomenal concepts from a linguistic perspective, i.e. as entities of speech, is a promising path. 
Sergei Kuzeev:

Language and Consciousness: Towards the Path of Synergy

Argumentum 16 (2020), 230-240

Debreceni Egyetemi Kiadó

DOI: 10.34103/ARGUMENTUM/2020/14

The paper consists of two parts: while the first section deals with the epistemological consequences of the Knowledge Argument and the existing accounts of phenomenal concepts, the second delineates three possible paths of conceiving relations between language and consciousness. These range from the long-established functionalist paradigm to the phenomenology-inspired synergetic account, which I treat in more detail, since it lays the foundation for the research program at hand and underpins my conviction that the study of phenomenal discourse - that is, of how phenomenal concepts are manifested in speech-will help elaborate new integral perspectives on consciousness, perception, and interpersonal communication.

\section{Knowledge Argument and Phenomenal Concepts}

Descartes is known to have once said: "One cannot conceive anything so strange and so implausible that it has not already been said by one philosopher or another" (Descartes 2007: 64). Indeed, be it in metaphysics or in a less noetic field, the philosophical pursuit has never scorned at eccentric and impractical argumentation, which, however, still had to follow one crucial rule to remain legitimate: to be logically conceivable. The reputable practice of bizarre, but solidly construed "thought experiments"-not unknown in natural sciences, where, as the proverbial Schrödinger's cat, they serve as graphic aids to the articulation of complex theories - has become somewhat of a common currency in the philosophy of mind. Thus, in the last decades of the $20^{\text {th }}$ century, Searle's "Chinese room" designed to argue against the "strong" artificial intelligence and, later, Chalmers' "philosophical zombies" refuting reductive physicalism transcended the boundaries of the academe and raised wide speculation in those fields, where understanding the human mind is a pressing necessity. Yet, it is Jackson's tale of "Mary the color scientist", first published in 1982, that deserves a detailed mention here to serve as the starting point in my argument.

In Jackson's scenario, Mary is a brilliant scientist who studies the neurophysiology of color vision and is well-versed in her field - that is, she knows virtually all there is to know on the subject. However, she has a predicament, and a serious one: since her very birth she has been locked up in a black and white room with no hint of colored objects in sightthough she has normal vision and knows color words, her real-life color experience was limited to shades of gray. ${ }^{1}$ Once released into the outside world, the tale goes, she sees the blue sky and exclaims: "Oh, now I know what it is to see the blue!". The question raised by Jackson to conclude the story is whether Mary indeed learned anything new about color from just seeing the blue of the sky (1982: 127-36).

Naturally, there can be two answers to that. Settling on "No" feels counter-intuitive: ${ }^{2}$ in the popular mind, direct experiences of things and phenomena surpass their descriptions, however detailed, in sensual richness; hence, our first impulse is to acknowledge that Mary did learn a certain aspect of blueness that she had been missing before despite her scientific scrutiny. But

1 Some argue that the experiment is ill-designed for the purpose: in fact, Mary could still have color experiences, for instance, in her dreams, or when she rubbed her eyes, etc. However, I hold that to remain argumentative thought experiments do not have to be rigorously realistic.

2 This is not to say that the "No" answer (sometimes termed as "thin" or "type-A" materialism) is universally rejected: some hold that Mary could have color experiences based on her scientific knowledge alone. See, for instance Dretske 1995: 82 and Dennett 2007: 14-31. 
Sergei Kuzeev:

Language and Consciousness: Towards the Path of Synergy

Argumentum 16 (2020), 230-240

Debreceni Egyetemi Kiadó

DOI: 10.34103/ARGUMENTUM/2020/14

answering this question in the affirmative-and this is what the Knowledge Argument amounts to - is again problematic, as it entails that physicalist accounts of the world are incomplete: they seem to leave out those peculiar experiential qualities, the "phenomenal character", that our intuition holds as purely mental (or immaterial), thus gravitating towards substance dualism or a similar doctrine. It is the persistence of this unwelcome intuition and its ontological consequences that make many scholars of the physicalist stance revisit the story time after time to contrive counter-arguments, if only in the form of half-way, temporary solutions.

A few years before Jackson, Nagel had delivered his speculations in a similar vein by asking his seminal question "What is it like to be a bat?", alluding to the impenetrability of phenomenal character by means of the existing scientific methodology (1974: 435-50). Just like Mary, who seems to lack the complete knowledge of colors in her pre-release situation, we are unable to experience the world from a bat's perspective despite our theoretic understanding of its echolocationary and other capabilities. This "what-it's-likeness" of subjective experience, also known as "qualia", has become a focus of increasingly technical and heated debates resulting, typically, in the acknowledgment of the "explanatory gap" - the alleged ungraspability of qualia in physicalist terms. And though this gap may be classified as either ontological or epistemological in nature based on one's philosophical affiliations, only a few would deny that it stands in need of further inquiry.

By admitting that Mary made an epistemological progress on her release by seeing the blueness of the sky (redness of tomatoes, greenness of the grass, etc.), we affirm that she brought it under a concept ${ }^{4}$ - in this case, a phenomenal concept that "we exercise when ... we notice or become aware of the phenomenal character of our experiences and feelings through introspection" (Tye 2009: 56). Thus, the simplest way to form or acquire phenomenal concepts (hereinafter-PCs) is to attend to what is happening here and now-what it feels like to touch a piece of fine cloth, hear street noises coming from the open window, or suffer from strain in the shoulders - and seize this particular feel in the form of an articulate thought, even if it is nothing more elaborate than "here it goes again". The qualia that are associated with these sensations (and that are the referents of the corresponding PCs) are philosophically idiosyncratic due to the involvement of subjectivity: they seem to be constituted by the way they appear to the subject and nothing else, as opposed to objective phenomena, whose reality is taken to be observer-independent. Many believe that the phenomenal quality thus construed causes the reality vs. appearance distinction to collapse and creates a form of incorrigibility that the habitual scientific apparatus is unable to interpret.

Phenomenal concepts must thus be discerned from all types of generic (or general) concepts, including perceptual concepts of sweetness, coldness, hunger, etc., which do not, in contrast with PCs, pick particular instances of experiences, just like the concept of "dog" does not refer to a specific dog, but to an idealized mammalian creature with a number of inalienable "doggish" properties. What is unique about PCs is their intrinsic subjectivity: put simply, the only legitimate way to possess someone's PCs is to be this someone, ${ }^{5}$ which means that PCs are inherently perspectival (or first-person only); inferentially isolated (non-

\footnotetext{
The term was introduced by the American philosopher Joseph Levine in 1983 (1983: 354-61).

4 Some argue that Mary's new knowledge is non-conceptual. Since this is a marginal view, I will not build on it here.

5 However, since we share a common endowment as human species, our phenomenal experiences remain, for the most part, intelligible and (at least indirectly) communicable.
} 
Sergei Kuzeev:

Language and Consciousness: Towards the Path of Synergy

Argumentum 16 (2020), 230-240

Debreceni Egyetemi Kiadó

DOI: $10.34103 / A R G U M E N T U M / 2020 / 14$

derivable from physical descriptions); experience-dependent (only acquired a posteriori, as a result of undergoing a relevant experience); and incorrigible (beyond the truth/falsity distinction) (Sundström 2001: 271).

Due to the volume limitations of this paper, doing justice to the strikingly rich body of work on phenomenal concepts is unrealistic, however, I will briefly mention some pivotal accounts that have been proposed lately, and whose principal aim consists in either defending or rebutting the Phenomenal Concept Strategy (hereinafter-PCS) - today's mainstream theoretical framework in the field. The primary objective of the PCS is to provide a conclusive critique of the dualist intuition that emerges from accepting the Knowledge Argument. The underlying idea of the PCS is to view the subjective character of Mary's color experience as a physical phenomenon, of which we may only think in non-physical terms. If Mary's puzzle is merely an effect of semantic isolation of PCs from physical concepts, the highly problematic ontological gap between the physical and the mental may be reduced, according to the PCS defenders, to the less problematic epistemological gap (Loar 1990: 81108). Put otherwise, the PCS holds that Mary acquires phenomenal knowledge of "[the] fact she already knew by means of a physical concept in her predicament" (Da Sa Pereira 2016: 134). Whether or not this tackles the entire problem is far from consensus, however, at least the following four PCS-based accounts have become influential:

1) In the recognitional (or type-demonstrative) account proposed by Loar, phenomenal concepts emerge through our direct acquaintance with instances of perceptual experiences (1990: 81-108). In difference from general concepts, which rely on theoretic knowledge, PCs rest on the ability to routinely recognize, discriminate, classify, and re-identify an object or an experience as "one of those" without even having a name for it (as, for instance, pre-linguistic infants discern between colors and shapes long before they acquire concepts of roundness, blueness, etc.).

2) According to the indexical account first developed by Perry, the primary function of PCs is to locate phenomenal content in time and space and to identify the speaker, which is akin to how such concepts as "I", "here" or "now" work (2001). A prototypic indexical statement involves an inner demonstrative pointing out to the phenomenal experience at hand ("this experience") and exhibits indexical knowledge, which is not about the apprehension of new facts, but about a new perspective on the facts already known.

3) In Papineau's quotational account, PCs are constituted by the very phenomenal experience to which they refer (1993). On this model, the structure of PCs is similar to a typical quotational utterance, for instance, "the word 'cat',", which contains an instance of the very word, to which it refers. Likewise, PCs may be conceived of as "the experience: ...", where the gap is to be filled by the relevant experience that is thus metaphorically quoted.

4) Finally, following the works of Dretske on the objective (mind-independent) character of information, the information-theoretic approach builds PCs upon general sensory concepts that are "doubled" as PCs following the introspection of phenomenal experiences. On this account, sensory and phenomenal concepts share the same cognitive structures and only differ in their semantic properties (Aydede \& Güzeldere 2005: 197-255).

Needless to say, the PCS and the specific accounts that fall within its scope have been facing diverse criticisms. Some argue that PCs as articulated by the strategy are either redundant for physicalism or should be interpreted in a different fashion (Ball 2009: 935-62; Tye 1999: 705-25), while others deny that the PCS is able to refute the Knowledge Argument (Chalmers 2007: 167-94). I will, however, briefly pitch upon another robust line of criticism 
Sergei Kuzeev:

Language and Consciousness: Towards the Path of Synergy

Argumentum 16 (2020), 230-240

Debreceni Egyetemi Kiadó

DOI: 10.34103/ARGUMENTUM/2020/14

known as illusionism about phenomenal consciousness. Intolerant to the anomalousness of the phenomenal character (its transparency, incorrigibility, perspectivalness, etc.), illusionists assume that phenomenal properties are physical properties misrepresented by introspection or, otherwise speaking, a cognitive illusion (Frankish 2016: 11-39). To make their point, illusionists will generally resort to the "magical" metaphor that likens our sensory system to a sleight-of-hand artist that makes us believe in the reality of the phenomenal without disclosing its underlying mechanisms. The purpose of this "magic show", some theorists suggest, is to make us more deeply engaged with the environment and help us develop the sense of self (Humphrey 2011). This doctrine, however, has been repeatedly accused of being a philosophical word play that trades one mystery for another. Furthermore, if phenomenal consciousness is an illusion, there still remains the question of who or what this illusion is originated by, which threatens infinite regress that a respectable philosophy needs to avoid.

There is, however, one enthusiastic adherent of illusionism-Daniel Dennett-who has been proselytizing among the PCS supporters with a relative success. While he likens phenomenal consciousness to a computer's graphical interface (with its illusionary "folders", "trash bin", etc.), in his "multiple draft model" the informative content of sensory inputs associated with PCs is always made available for introspection as a coherent text. According to Dennett, what we refer to as the phenomenal character is merely an operational metaphor, or a linguistic fallacy, while the subjective experience itself is none other than a narrative stream. Dennett denies the reality of mental imagery prior to linguistic fixation of the sensory content: in his view, instead of mental images (that are a central tenet of representationalism), what we continuously entertain in our cognitive domain is speech formulae. The subjectivity can thus be explained by propositional dispositions, that is, by the results of human cognitive activity that submits to the established semiotic, logical, and linguistic conventions (1991: 247, 389). It follows from Dennett's theory that the study of consciousness is potentially reducible to the study of how these phenomenal narratives are produced. Though far from being an intuitive truth, this assumption may, I think, shape further developments in explaining phenomenal consciousness, and in the next chapter I will elaborate on certain consequences of Dennett's argument, while steering clear of his reductionism. ${ }^{6}$

\section{Phenomenal Concepts and Language}

The core idea of Dennett's theory is that phenomenal concepts are linguistic construals giving rise to (the illusion of) phenomenality: we never have direct contact with the contents of our own conscious experience, hence, it is the language that creates a semblance of such access and enforces on us a naïvely realistic view of our phenomenal life. If we are to take this idea seriously and extend it beyond the discourse of perception, we must endow language with the truly impressive ability of shaping our full-fledged selves: paraphrasing Austin, the question then is not about what we do with words, but about what words do with us. ${ }^{7}$

As it stands, this view has been contested all too often on the grounds of the commonsensical intuition that pre-linguistic infants and (at least some) animals seem to have

6 Dennett's general response to the Knowledge Argument is reductively physicalist. That is, he holds that Mary could know perfectly well what it felt like to see colors before her release (Dennett 2007: 14-31).

7 The title of J. L. Austin's most influential book published in 1955 is "How to Do Things with Words". 
Sergei Kuzeev:

Language and Consciousness: Towards the Path of Synergy

Argumentum 16 (2020), 230-240

Debreceni Egyetemi Kiadó

DOI: $10.34103 / A R G U M E N T U M / 2020 / 14$

phenomenal experiences and to be able to efficiently process experiential data beyond their instinctual capabilities. Following the recent revival of philosophical interest in the subject, this controversy grew into a rich body of both speculative and experimental research of the relations between language and consciousness. That said, however, it remains grossly dominated by the (hard) problem of consciousness, ${ }^{8}$ not of language that is routinely ignored or reduced to "a kind of peel, an external crust which has no influence on the mechanism of pure thought" (Berta 2011: 188). On this approach, being equipped with language means being able to make propositional references to one's own phenomenal experiences, but never to instantiate them. PCs in this scheme of things are the essential cognitive entities of the epistemic chain that make language possible:

It is evident that even without the use of verbal symbols, we and higher animals use phenomenal concepts to recognize and to think about the perceptual elements of the world. Thus, phenomenal concepts could be conceived as the most basic and oldest phylogenetic components of conscious thinking, which preceded the development of language and propositional concepts by many millennia (Musacchio 2005: 411).

This idea of autonomy of consciousness and of its precedence over language- - let it be our first path among the other alternatives, the path of disavowal-is the prevailing thesis of functionalism, the mainstream current of thought in today's cognitive science. ${ }^{9}$ However, even its ardent supporters would typically admit that this picture is not all-encompassing and that there emerge hard-to-explain linguistic effects if one is appreciative enough of the complex social and cultural environment that we, as human species, have built thanks to our aptitude for symbolic communication. To accommodate this interference, there have been attempts to negotiate a consensual theory that holds, according to Zlatev, that "language cannot have strong effects on the 'basic layers' of consciousness, [...] but it may very well have such a role when it comes to the 'higher levels' involving self-regulation, reasoning, an autobiographical self and even the understanding of others" (Zlatev 2008: 11). This line of reasoning is seen by many as a middle ground which helps interpret much of the available evidence, but it is still far from consensus that it can efficiently tackle some of the pressing problems - of language acquisition, embodiment, tacit semantics, to name just a fewwithout a thorough re-design of its initial premises.

Those who set their feet on the second path, the path of epistemic doubt, unleash the floodgates for relativism and indeterminacy, since they focus on the disconcerting questions that positivism prefers to ignore: can we make reliable assumptions about our mental life while being at once its experiencers and observers? Can we study consciousness and language if the means of this inquiry are the objects of study themselves? Can we consistently explore phenomena that are the sources of their own structure? Answering any of these (and similar) questions in the negative leads one to the conviction that the comprehensive science of the mind (at least the one modelled around a positivist doctrine) is hardly a possibility, as we have no means of transgressing the matrix of pre-theoretic restrictions that consciousness and language enforce upon us - the science that does not recognize the effects of this quagmire

8 The "hard problem of consciousness", as formulated by D. Chalmers, consists in our virtual inability to explain in materialistic terms why sentient beings have qualia (Chalmers 2007).

9 Functionalism about consciousness holds that mental states (thoughts, sensations, etc.) are constituted by their functional roles rather than by their internal constitution, i.e. that they are determined by their causal relations to sensory stimuli. 
Sergei Kuzeev:

Language and Consciousness: Towards the Path of Synergy

Argumentum 16 (2020), 230-240

Debreceni Egyetemi Kiadó

DOI: $10.34103 / A R G U M E N T U M / 2020 / 14$

delivers only an illusion of objective knowledge. An interesting re-iteration of this view was set forth by McGinn in his renowned essay "Can We Solve the Mond-Body Problem?", where he suggests that the task of solving the consciousness debate is simply beyond the mental capacity of humans, just like understanding quantum theory is beyond the mental capacities of apes, let alone other animals (1989).

However, being a follower of the second path is not always the recognition of defeat - for some, it is a call to action. What nourished the once booming tradition in analytical philosophy - upheld by Russell, Wittgenstein, Kripke, Frege, and Quine, to name but a fewwas the ambition of liberating the scholarly discourse from the distortions of profane talk and of dispelling the wizardry of everyday language, since "philosophy is a battle against the bewitchment of our intelligence by means of language" (Wittgenstein 1997: §109). These "rectification" attempts had gone into diverse directions and grew into a variety of research programs (with the evolution of Wittgenstein's views as the epitome of this diversity), but were largely undermined by the advance of post-structuralism, which sought to aestheticize the gap between language and consciousness (and the world at large), rather than to bridge it. Building on Nietzsche's nihilism, Heidegger's hermeneutics, and Husserl's phenomenology, continental post-structuralists - with Derrida, Deleuze, and Bart at the forefront of the leaguetried to secure the position that language always comes before metaphysics, that we, following the famous idea of Lacan, are somehow "born into it", and that the analytical discourse is, at best, a mind-invigorating exercise rather than a solution to the riddle. The only consolatory conclusion that this outlook affords is, perhaps, that though language is a verdict, it is not necessarily a horrid one.

Intriguing as they are, these speculations now bring me closer the third — and final—path of collating language and consciousness, a path that swerves back to where I started: the Knowledge Argument and the Phenomenal Concept Strategy that it sets into motion. This is the path of synergy, which, similarly to Dennett's proposition, entitles language to be the birthplace of our phenomenal selves. Another philosopher of mind, Carruthers, explores this possibility within the so-called "higher-order theory", in which "consciousness is constituted by an accessibility-relation to occurrent thinkings, where those thinkings are conscious in turn (that is, where they are regularly made available to further occurrent thinkings, which are, if they occur, in turn made available to yet further thinkings, and so on)" (1996: 194). What he suggests, in brief, is that phenomenal concepts are an inevitable consequence of our being aware of the phenomenal states that we are in, and that this awareness is achieved through thinking of them in propositions of natural language, i.e. through maintaining an inner monologue about what we feel. Indeed, one cannot fail to notice that whatever we do, from the moment we recover from sleep, we hear an inner voice inside our head even when we do not speak aloud; it seems to accompany our every conscious mental state, though not necessarily as a coherent narrative (as grasped by Joyce, Faulkner, and other writers in their "stream of consciousness" technique), and we normally attribute this voice to ourselves (in difference from schizophrenic patients with auditory hallucinations).

Some might object to the idea that having the linguistic ability is all it takes to be phenomenally conscious. Their principal counter-argument is that not all thinking is verbal and that, hence, phenomenal states appear ineffable. This is, I think, a misconstrued objection, since it fails to distinguish between phenomenal thoughts, which can be grasped, tentatively, as "I have this feeling of $\mathrm{X}$ " (where $\mathrm{X}$ stands for a perceptual experience), and phenomenal descriptions of subjective feels (i.e., speaking of what experiencing things "feels like"). 
Sergei Kuzeev:

Language and Consciousness: Towards the Path of Synergy

Argumentum 16 (2020), 230-240

Debreceni Egyetemi Kiadó

DOI: $10.34103 / A R G U M E N T U M / 2020 / 14$

Phenomenal thoughts seem to always be verbal once we attend to them, while phenomenal descriptions are indeed notoriously resistant to direct verbalization, which does not threaten the overall account and may be explained by the incongruence between the "analogue" sensual inputs and the (largely) "digital" nature of the linguistic code. Moreover, even this seeming ineffability is only relative, since, according to Dennett, "what it feels like to see Paris by moonlight in May can be adequately conveyed in a few thousand words (an empirical estimate based on the variable success of actual attempts by novelists)" (2005: 115).

Hence, the third path rest on the premise that phenomenal knowledge is linguistically mediated-without this mediation, phenomenal character does not fully emerge, and experiences themselves either remain transparent in a strong sense (just like the exact number of objects is transparent to infants before they learn to count) or have a different, pre-theoretic quality that may still be conceivable. ${ }^{10}$ In difference from Dennett, who starts off by explicitly discarding the Knowledge Argument and assuming that phenomenal character is created entirely by linguistic means, I only suggest that language makes it cognitively accessible (in the form of propositional thought) and, consequently, "thickens" it with qualitative dimensions (intensity, localization, relevance, etc.). The extent to which this idea is scientifically plausible is subject to further evidence from cognitive research, but what we can do, meanwhile, is to start treating qualia not only as entities of thought, but, also, as entities of speech, for it is beyond doubt that, in addition to having phenomenal thoughts, we communicate phenomenal contents (despite the oft-raised claims of their ineffability ${ }^{11}$ ) via public language in a wide range of contexts.

Such statements, which refer to qualia of sensual (perceptual, emotional, bodily) experiences that emerge as phenomenal concepts on the level of introspection, are sometimes dubbed as phenomenal judgments ${ }^{12}$ (Argonov 2014; Chalmers 1996: 161) and might be viewed as the building blocks for phenomenal discourse. As noted above, phenomenal concepts manifest their subjectivity through an indexical or recognitional reference ("I have this feeling"), which, in order to be communicated meaningfully, needs to be converted to an informative statement. In the spoken register we routinely achieve this goal by simply picking a public name for the sensation at hand, wherever possible, ${ }^{13}$ as in "I am in pain", "I feel sad" etc., but should we need more subtle and fine-grained descriptions, they can be extended to form phenomenal judgments, which purport to answer Nagel's question of "what is it like?". These are a hallmark of literary discourse, where they may take various shapes and (somewhat inevitably) involve figurative language, to wit:

(1) That is how I feel: white, flat, thin. I feel transparent (Atwood 1986: 267).

10 To the same degree as non-linguistic thought is in principle conceivable.

11 As is shown elsewhere, claims of strong ineffability are self-defeating. In this case, they should be re-iterated as claims of impossibility of direct reference (for a detailed overview, see Liang 2011).

12 In analytical literature, this term has no set scope of use and might be understood, rather loosely, as "words, discussions, and texts about consciousness, subjective phenomena, and the mind-body problem" (Argonov 2014, 53).

13 Clearly, not all mental states have names in public language. For instance, little can be said about Mary from Jackson's thought experiment, except that she has a feeling that "typically arises when looking at blue objects". The same holds true for incompetent speakers unable to pick right names for their mental states. 
Sergei Kuzeev:

Language and Consciousness: Towards the Path of Synergy

Argumentum 16 (2020), 230-240

Debreceni Egyetemi Kiadó

DOI: $10.34103 / A R G U M E N T U M / 2020 / 14$

(2) I sink down into my body as into a swamp, fenland, where only I know the footing. Treacherous ground, my own territory. I become the earth I set my ear against, for rumors of the future (Atwood, 1986: 63).

Both (1) and (2), in my interpretation, are phenomenal judgments of a varying degree of intricacy: in difference from the trivial statements that we tend to exchange in the everyday settings, these clearly involve a qualitative reference, one way or another. Of course, admitting that judgments of the sort are the most (or the only) sensible way of communicating qualia does raise a host of questions - about their reducibility to a prototype, reliance on figurative language, communicative strategies that they employ, and many others. Linguistic interface of subjectivity is still a relatively unexplored territory, but it is my conviction that following this path will bring us closer to the understanding of how language helps us be selfaware, for " ... if we admit that sensations are forms of organism-environment relationship, and that this environment is not only physical, but also inherently and evolutionary symbolic to such a degree that the linguistic dimension has altered the cognitive features of the organism itself, then we might find a new way to understand qualia" (Berta 2011: 205).

\section{Conclusion}

Today's science of consciousness may still be in its infant stage, with all unsettling signs of immaturity - perplexing hypotheses, contradictory theories, and excessive reliance on speculative thought - in plain view. However, what slowly but steadily emerges from this prebiotic soup is the holistic picture of the human mind based on the insight that the traditional computational models fail to explain the mental in its entirety. One of the reasons for this failure, I assume, is the persistent inertia of many scholars (and whole schools of thought) in adopting the idea that the mind is not only a product of biological evolution, but of the culturally and socially mediated environment that we inhabit. Our ability to communicate symbolically through language is an indispensable part of this environment and, once acquired, is a game-changer for human cognition and perception. Therefore, the systematic study of language from the cognitive perspective, already well underway, combined with the focus on interpersonal communication, is able to elucidate the nature of the mental from both epistemological and ontological perspectives-something that the mainstream analytical philosophy and linguistics of the previous century were too undetermined to contend.

Jackson's Knowledge Argument seems a vantage starting point in this research, as explorations of phenomenal consciousness from various angles give rise to the question of the role of language in the acquisition of phenomenal knowledge. Since the existing evidence points in the direction of this role's prominence, I suggest that cognitive linguistics should develop a new agenda of phenomenal discourse - the study of structure, linguistic patterns, and use of phenomenal propositions across various genres and speech modes. This contribution may be of the utmost value in the interdisciplinary research of phenomenal consciousness and the human mental life in general. 


\section{References}

Atwood, Margaret (1986): Handmaid's Tale. New York, NY: O. W. Toad Ltd.

Argonov, Victor (2014): Experimental Methods for Unraveling the Mind-Body Problem: The Phenomenal Judgment Approach. The Journal of Mind and Behavior 35 (1/2), 51-70.

Aydede, M. \& Güzeldere, G. (2005): Cognitive Architecture, Concepts, and Introspection: An Information-Theoretic Solution to the Problem of Phenomenal Consciousness. Nôus 39, 197-255. https://doi.org/10.1111/j.0029-4624.2005.00500.x

Ball, D. (2009): There Are No Phenomenal Concepts. Mind 118 (472), 935-962. https://doi.org/10.1093/mind/fzp134

Berta, L. (2011): Qualia from the Point of View of Language. The Journal of Mind and Behavior 32/5, 181-208.

Carruthers, P. (1996): Language, Thought, and Consciousness. Cambridge, UK: Cambridge University Press. https://doi.org/10.1017/CBO9780511583360

Chalmers, David (1996): The Conscious Mind: In Search of a Fundamental Theory. Oxford, UK: Oxford University Press.

Chalmers, D. (2007): Phenomenal Concepts and the Explanatory Gap. In: Alter, T. \& Walter, S. (eds.): Phenomenal Concepts and Phenomenal Knowledge. New Essays on Consciousness and Physicalism. Oxford, UK: Oxford University Press, 167-94. https://doi.org/10.1093/acprof:oso/9780195171655.003.0009

Dennett, D. (1991): Consciousness Explained. New York, NY: Penguin Books.

Dennett, D. (2005): Sweet Dreams. Philosophical Obstacles to the Science of Consciousness. Cambridge, MA: The MIT Press. https://doi.org/10.7551/mitpress/6576.001.0001

Dennett, D. (2007): What Robo-Mary Knows. In: Alter, T. \& Walter, S. (eds.): Phenomenal Concepts and Phenomenal Knowledge. New Essays on Consciousness and Physicalism. Oxford, UK: Oxford University Press, 14-31. https://doi.org/10.1093/acprof:oso/9780195171655.003.0001

Descartes, R. (2007): Discourse on Method. Indianapolis, IN: Focus Publishing.

Dretske, F. (1995): Naturalizing the Mind. Cambridge, MA: MIT Press.

Frankish, K. (2016): Illusionism as a Theory of Consciousness. Journal of Consciousness Studies 23 (11-12), 11-39.

Humphrey, N. (2011) Soul Dust: The Magic of Consciousness. Princeton, NJ: Princeton University Press. https://doi.org/10.1515/9781400838073

Jackson, F. (1982): Epiphenomenal Qualia. Philosophical Quarterly 32, 127-36. https://doi.org/10.2307/2960077

Levine, J. (1983): Materialism and Qualia: The Explanatory Gap. Pacific Philosophical Quarterly 64, 354-61. https://doi.org/10.1111/j.1468-0114.1983.tb00207.x

Liang, Ruiqing (2011): Digitality, Granularity, and Ineffability. Language Sciences 33, 3039. https://doi.org/10.1016/j.langsci.2010.08.010

Loar, B. (1990): Phenomenal States. In: Tomberlin, J. (ed.): Philosophical Perspectives 4: Action Theory and Philosophy of Mind. Atascadero, CA: Ridgeview, 81-108. https://doi.org/10.2307/2214188

McGinn, C. (1989): Can We Solve the Mind-Body Problem? Mind 98/391, 349-366. https://doi.org/10.1093/mind/XCVIII.391.349

Musacchio, J. M. (2005): The Ineffability of Qualia and the Word-Anchoring Problem. Language Sciences 27 (4), 403-435. https://doi.org/10.1016/j.langsci.2004.10.004 
Nagel, T. (1974): What Is It Like to Be a Bat? Philosophical Review LXXXIII (4), 435-450. https://doi.org/10.2307/2183914

Papineau, D. (1993): Philosophical Naturalism. Oxford, UK: Blackwell.

Perry, J. (2001): Knowledge, Possibility, and Consciousness. Cambridge, MA: The MIT Press. https://doi.org/10.7551/mitpress/4077.001.0001

Sundström, P. (2001): Phenomenal Concepts. Philosophy Compass 6/4, 267-81. https://doi.org/10.1111/j.1747-9991.2011.00384.x

Tye, M. (1999): Phenomenal Consciousness: The Explanatory Gap as a Cognitive Illusion. Mind 108 (432), 705-725. https://doi.org/10.1093/mind/108.432.705

Tye, M. (2009): Consciousness Revisited. Cambridge, MA: The MIT Press. https://doi.org/10.7551/mitpress/9780262012737.001.0001

Wittgenstein, L. (1997): Philosophical Investigations. Hoboken, NJ: Wiley-Blackwell.

Zlatev, J. (2008): The Dialectics of Consciousness and Language. Journal of Consciousness Studies 15 (6), 5-14.

\section{Sergei Kuzeev}

Eötvös Loránd University of Budapest

Doctoral School of Linguistics

sergei.kuzeev@gmail.com 